International Journal of Business Management, Entrepreneurship and Innovation, Volume 2, Issue 1, 2020, PP 36-51, ISSN 2707-8027

[IJCAB

\title{
Personal Selling Strategies and Customer Loyalty among Insurance Companies in Malindi Town, Kilifi County, Kenya
}

\author{
Arori Moriasi Abel' ${ }^{1}$, James Maina Rugami² \\ ${ }^{1}$ Student, Master of Business Administration (Marketing Option), Kenyatta University, Kenya \\ ${ }^{2}$ Lecturer, Department of Business Administration, Kenyatta University, Kenya
}

\begin{abstract}
The study examined the influence of personal selling strategies and customer loyalty among insurance companies in Malindi town, Kilifi County, Kenya. The study adopted a descriptive research design. The targeted population was 967 employees working in the selected four insurance companies in Malindi, namely Gateway insurance company limited, Marangi insurance agency, Blue shield Company Limited, Tausi Insurance Agency. The unit of analysis was a sales manager, salespersons and customers. SPSS was used to organize code and analyze information and generate the quantitative report. The data were analyzed using descriptive and inferential statistics. The study concluded that selling strategy, Systems selling strategy, Features selling strategy and Consultative personal selling strategy was positively and significantly associated with customer loyalty. Moreover, the study concluded that selling strategy, Systems selling strat, Features selling strategy and Consultative personal selling strategy were positively and significantly related to customer loyalty. The examination recommended that the insurance agencies in Malindi can utilize the canned selling technique, system selling methodology, features selling system and individual consultative strategy to build the devotion of the clients since they have a personalized experience. Moreover, the research suggests that based on the level of completion in the market, the management in all insurance companies in Kenya to carry out various personal selling strategies to enable the companies to grow and diversify their portfolio to minimize losses and cut down the cost thus enhancing their competitiveness. Moreover, the study recommended systems selling strategies should be put in place to improve operational efficiency and improve the decision-making process to increase their performance. The study also suggested insurance to be more involved in advocating selling their products by clearly establishing the features of a product before making the presentation and to be revealing all the components of any product without hiding any information.
\end{abstract}

Key Words: Personal Selling Strategies, Canned Strategy, System Strategy, Features Strategy, Consultative Strategy, Customer Loyalty, Insurance Companies

DOI: $10.35942 /$ jbmed.v2i1.99

\section{Cite this Article:}

Arori, A., \& Rugami, J. (2020). Personal Selling Strategies and Customer Loyalty among Insurance Companies in Malindi Town, Kilifi County, Kenya. International Journal of Business Management, Entrepreneurship and Innovation, 2(1), 36-51. https://doi.org/10.35942/jbmed.v2i1.99 
International Journal of Business Management, Entrepreneurship and Innovation, Volume 2, Issue 1, 2020, PP 36-51, ISSN 2707-8027

[IJCAB

\section{Introduction}

Selling strategies are fundamental for the retention of the customers in any of the organizations. According to Mbugua (2014), selling strategies are different approaches undertaken by the seller to attract more customers in the organization and outdo the competitors hence improved in its performance. The performance of the institutions is achieved when the organizations are in a position to expand in its operation by retaining existing customers and attracting the new ones (Jumaev \& Hanaysha, 2017). Cheserem (2016) revealed that the customer retention is one of the most difficult challenges that face many of the organization in the World noting that are many business organizations which are competing to increase their revenue through expanding their market. Furthermore, customer loyalty is one of the instruments utilized, yet it has been confronting difficulties which are identified with inward and outer issues inside the associations (Auka, 2015). According to Adesoga (2016), the problems affecting the execution of the duties within an institution can be associated with the nature of the company or influenced by the employees. The organization has command over the procedure, yet the workers on the ground do the last execution. Moreover, Auka, Bosire and Matern (2015) reported that personal selling strategies could be defined as the strategies that are applied by the salesperson in the companies to convince the customers to purchase their products. According to Waithaka (2014), personal selling strategies entail developing the relationship between the customers, discovering and communicating the necessities of the customers and coordinating the suitable items with these requirements. Mbugua (2014) showed that personal selling strategies comprise of canned particular selling strategy, system personal selling strategies features personal selling strategy and consultative personal selling strategy.

The canned personal selling strategies can be achieved when the employees in a company are involved in providing motivation to the customers until an accord is landed at, give the subtleties that address the issues of the customers and encourages the seller to follow the inclination of the customers (Cheserem, 2016). Likewise, Ondieki et al. (2014) revealed that the system individual selling strategy is a typical technique utilized by any association, particularly the financial institutions in which the firms market their products through selling the products as a package instead of selling them separately which enables to sell in large quantities. According to Auka, Bosire and Matern (2015), companies use personal selling strategy and the salespersons' associates to persuade the buyers to consume a particular product and therefore, the features of the products must be in a position to meet the needs of the prospective buyers Oketch (2014). Moreover, Tapera and Gororo (2016) showed that in consultative personal selling strategy, salesperson associates with customers and understand the problem that the customer is trying to solve. Therefore, the salesperson tries to help solve that problem.

As indicated by Banerjee (2014), personal selling upgrades product advancement and it is the most useful advertising specialized mechanism that ought to be grasped by Indian home insurance firms to expand customers. Further, according to Moghareh Abed and Haghighi (2016) customeroriented selling, versatile selling and traditional technique add to the making of intense and a long- lasting emphatic bond with customers in the insurance organizations in the United Kingdom. Besides, Ocon and Alvarez (2014) contended that that personal selling encourages the innovative deal and improves the picture of the organization well to the customers and still turns out to be most applicable and an essential achievement factor in the present showcasing exercises regardless of the coming of advanced promoting in the Philippines. As per Carelse (2017), changing the nature of the administration offered to the customers and improving offering explanations to the 
International Journal of Business Management, Entrepreneurship and Innovation, Volume 2, Issue 1, 2020, PP 36-51, ISSN 2707-8027

[ICAB

product that it can solve their problems increases loyalty, particularly to life insurance in South Africa. In Ethiopia, Mamo (2015) found that proper selling techniques were decidedly identified with the presentation of the NIB insurance company. Likewise, Tapera and Gororo (2016) stated that personal selling and publicizing were primarily utilized as the principle limited time methodologies among Zimbabwean Insurance organizations for making the upper advantage.

In Kenya, Cheserem (2016) found out that the role of the advertising channels does not just concentrate on the interest fulfillment by offering products but also to stimulate request through data, making proximity and advancement by the customer and the client comfort is an example of the indicators of business execution measurements. Further, Oketch (2014) found that there are different estimates set up to hold the customers at the association, including a committed customer organization office, streamlining claims and usual subsequent meet-ups to the customers. Akinyi (2011) investigated the impacts of particular trading on sales and discovered that personal selling affected sales. Musyoki (2009) looked into the effect of personal selling on sales and found that there is no considerable differential in actuality on sales. This distinction may have been brought about by geological variety as Akinyi developed her examination in an agricultural setting while Musyoki looked into town setting. Mbugua (2014) investigated personal selling methodologies and execution of pharmaceutical firms in Nairobi and discovered that the organizations were utilizing their selling procedures to advance and market their items, which brought about improved performance.

In Kenya, the Insurance industry is regulated by the Insurance Regulatory Authority (IRA). 44 Insurance companies in Kenya operate under the umbrella body, the Association of Kenya Insurers (AKI) (Oketch, 2014). Its objective is to enhance prudence business practices, accelerate the growth of business and create awareness among the public. However, the 44 licensed insurance companies in Kenya compete for a minimal market. Other challenges facing the industry, include the low disposable income for a massive percentage of the population, inadequate tax incentives, poor saving culture and inappropriate information among the public (Mbugua, 2014). The insurance sector plays a very significant role in the economy, for instance, promoting trade by providing risk cover, creation of employment opportunities and giving the government funds through taxes to develop the economy (Auka, Bosire \&Matern, 2015). Insurance companies are very fundamental in any of the economies in the World. According to Cheserem (2016), the insurance companies are involved in offering financial protection to the customers, helps the businesses to continue operating since it mitigates out the business risks and give them the confidence of compensation in case of any danger. Furthermore, the insurance companies inject some of their profits to finance the economic developments in the economy and they are a source of employment to the members of the society (Adesoga, 2016).

Currently, there are four insurance companies in Malindi, namely: Gateway insurance company limited, Marangi insurance agency, Blue shield Company Limited and Tausi Insurance Agency. Further, despite a lot of uncertainties in life, only a few of the Kenyans have taken initiatives to get insured, people with low incomes Waithaka (2014) particularly. This means that the collapse of many of the small businesses and the increase of the poverty levels may have been attributed to the ignorance of most people to get insured against any of the unforeseen risks. Moreover, the marketing strategy used by the companies will determine its sustainability and extent to the market share. According to Kwak, Anderson, Leigh and Bonifield (2019) set up that the Personal selling is one of the best approaches used to convey to clients and it demonstrates the image of the company to the public through being the expensive mode of product promotion. 
International Journal of Business Management, Entrepreneurship and Innovation, Volume 2, Issue 1, 2020, PP 36-51, ISSN 2707-8027

[i] $C A B$

\section{Statement to the problem}

Personal selling has been known to be a great contributor to sales in most industries due to its individual touch and the development of the relationship with the customers. The competition among the insurance companies is very high and they are adopting all means of marketing approaches to be in a position of making high sales. As indicated by Linge and Sikalieh (2019), the development of the insurance business and penetration to the Kenyan market is low. Additionally, Njoroge (2019) detailed that a portion of the insurance agencies in Malindi has been unsustainable and others have opted to shut because of poor promoting abilities and others are revealing a decrease in their income, bringing up concerns on their advertising systems. Moreover, Khasaya (2018) demonstrated that the change of policyholders is a distressing task that relies on the expert to develop reliable strategies in persuading the clients to purchase insurance products and services.Notwithstanding, none of the examinations have inquired about the role of personal selling procedures and client loyalty among insurance agencies in Malindi town, Kilifi County, Kenya. For instance, the investigation done by Moghareh Abed and Haghighi (2016) looked at the impact of selling techniques on deals execution in the assurance firms working in Bingley, United Kingdom, displayed the conceptual gap. The particular destinations that guided the investigation were to look at the impact of customer- oriented selling, versatile selling, social system on sales execution. Likewise, Tapera and Gororo (2016) examined the effect of advertising, internet marketing and personnel selling strategy on creating a competitive advantage in Zimbabwean insurance companies. A cross-sectional survey methodology was used and data analyzed using the content analysis.

This study presents a conceptual and methodological gap. Moreover, Mbugua (2014) showed the contextual difference. The investigation analyzed the proper selling techniques and execution of pharmaceutical firms in Nairobi. Additionally, Auka, Bosire and Matern (2015) researched the apparent assistance quality and client steadfastness in retail banking in Kenya. The study presented the contextual gap with the current study since it was not done in insurance companies. Moreover, the specific objectives that were used by the survey by Cheserem (2016) were the influence of branding, product marketing, price considerations and location on customer loyalty in fast-food restaurants in Nairobi. The study presents both the conceptual and contextual gaps since the objectives used were not similar to that of the current research, and it was not conducted in the insurance industry. Therefore, studies have presented a knowledge gap and thus, the current research will bridge these gaps and attempt to answer the question; does a personal selling strategy have an influence on customer loyalty among insurance companies in Malindi town, Kilifi County, Kenya.

\section{Research Hypotheses}

i. There is no significant effect of canned strategy on customer loyalty among insurance Companies in Malindi sub-County.

ii. There is no significant effect of system strategy on customer loyalty among the insurance Companies in Malindi sub- County.

iii. There is no significant effect of features strategy on customer loyalty among insurance Companies in Malindi sub- County.

iv. There is no significant effect of consultative strategy on customer loyalty among insurance Companies in Malindi Sub-County. 
International Journal of Business Management, Entrepreneurship and Innovation, Volume 2, Issue 1, 2020, PP 36-51, ISSN 2707-8027

[IJCAB

\section{Literature Review}

\subsection{Theoretical review}

\subsubsection{AIDA theory}

The AIDA theory was developed by the American businessman, Elmo Lewis in the year 1898 (Javan, Khanlari Motamedi \& Mokhtari, 2018). According to Lewis, advertising is very critical to maximizing the revenue of the company, particularly the interaction between the seller and the buyers concerning the product (Lee, Song, Lee \& Petrick, 2018). Besides, Lewis built up that the item should draw in the consideration of the clients and the enthusiasm for the items from the consumers should be aroused. Additionally, when the benefits in the products have been initiated, it becomes the seller's task to persuade the customer that they want to own this product and this must be transferred into action, that is, the purchase (Hawaldar, 2018). However, AIDA theory was criticized by scholars. For instance, Wijaya (2015) established that the approach does not take into consideration the level of satisfaction and dissatisfaction of the consumers as a result of the advertising. Additionally, another significant deficiency of the theory is the nonattendance of postbuy impacts of utilization, rehash support conduct and other post-buy social goals, for example, referrals or taking part in the readiness of online item audits. Also, Rehman, Nawaz, Khan and Hyder (2014) found the theory was only involved with how to improve the methods of customer attraction but did not elaborate on the adverse effects associated with the surplus purchase of the products. Furthermore, the selection of the system by firms advances colossal development of the organizations regarding customer base and income (Prathapan, Sajin \& Zakkariya, 2018.) AIDA model established a positive and noteworthy relationship with increasing the level of customer attraction and satisfaction through product promotion. Companies that have used the model as a promotional strategy have improved in the performance level and the growth and sustainability increased over time (Cramphorn, 2006). Therefore, the theory was relevant to the current study since and will help to conclude the influence of personal selling strategies on customer loyalty.

\subsubsection{Commitment Trust Theory}

The commitment trust theory was put forward by Morgan and Hunt in 1994. The theory depicts a relationship to be successful and reliable, there should exist a strong commitment and trust from both parties involved in any form of transaction. The theory clearly articulates that words companies should develop commitment and trust towards their customers to build a strong relationship with them to enhance the performance. Moreover, as per Friman, Gärling, Millett, Mattsson and Johnston (2002) trust is very crucial and it is all about confidence from both parties who are in the relationship and ensuring they deliver their promises at the stipulated time. Further, the theory reveals that commitment is a long term relationship that is built by both parties to ensure they maintain the value of the partnership. MacMillan, Money and Downing (2005) argued that commitment trust theory is very applicable to the businesses units as it outlines the significance to continue to invest in the relationship with their customers through a series of building-related activities and also being committed to them.

However, according to Zinkhan (2002), the theory failed to examine the costs that are incurred in retaining the customer in the organization. The theory was unable to calculate the time that it takes to cultivate the relationship with the customer properly; it can be very much time-consuming in both execution and culmination. Furthermore, according to Sun and Zhang (2006), the theory failed to examine the influence of the attitude, norms and culture of the customers in the process 
International Journal of Business Management, Entrepreneurship and Innovation, Volume 2, Issue 1, 2020, PP 36-51, ISSN 2707-8027

[IJCAB

of maintaining the relationship in which the management decides the marketing strategy without considering the belief, culture and the norms towards the products. The theory was relevant to the current study as it established that the primary purpose why companies advocated for the relationship with the customers. The approach had shown that creating a good relationship with customers was to encourage cooperation from both parties, discourage firms from coming up with short term alternative clients instead of long term clients and lastly allows the company to take the risk knowing that they have committed customers who trust the company. Relationship marketing is all about forming a bond with customers by ensuring the firm meets the needs of the customers. Also, the theory showed that most of the companies would better invest in the long term bond with the customers rather than the short term bond. Therefore, when customers trust the services and goods of the company, they become loyal to that company; hence, a mutual benefit is developed among the parties. The theory was much applicable to the study because it was able to explain the relationship between personal selling strategies and customer loyalty.

\subsubsection{Social Exchange Theory}

The theory was developed by Blau who concentrated on personal circumstance in human social connections (Coyle \& Diehl, 2018). The theory states that the market exchanges happen efficiently and more successfully when both customer and company expect to gain value by participating in the transaction. The theory mostly emphasized on how participation in an activity will give a benefit to everyone participating in an individual event without one benefiting at the expense of another one (Ghafari, Yakhchi, Beheshti \& Orgun, 2018). Moreover, the theory faced criticism. One of the setbacks of the social exchange theory is that it neglects the contexts of the culture in society (Cropanzano, Anthony, Daniels \& Hall, 2017). The approach is based on the rewarding systems only but not all the cultures in the nation are the same and some communities will not be impressed by any rewarding initiative in the society. Also, the theory is not in a position to illustrates clearly unselfishness and the actions of human beings, it assumes the perceptions of an individual of what is considered as the reward and what might be viewed as the punishment and thus, Cropanzano and Mitchell (2005) revealed that the theory lacks sufficient and reliable theoretical precision, and thus has limited utility (Chernyak \& Rabenu, 2018). Despite criticism of the theory by scholars, it establishes an economical approach to relationships that can help to get to the bottom line of the matter very quickly (Yan, Wang, Chen \& Zhang, 2016). In case the costs are surpassing the favorable circumstances or if a comparable choice is open, by then it's an incredible chance to end. Social exchange theory is very crucial and companies can invest in these relationships to improve their image and establish a favorable market exchange and finally gain value. The Social exchange theory is very relevant to the current study and will be used to illustrate the role of sponsorship of events as a strategic marketing communication tool and performance of Safaricom Company.

\subsubsection{Relationship marketing theory}

The theory was proposed in 1996 by Buttle. According to Buttle (1996), organizations should be more focused on the client faithfulness and the long haul commitment with the client rather than just the short term goals such as the customer purchase and the sales to be made per the person. According to Möller, Halinen (2000), relationship marketing theory is fundamental to business organizations as it is all about creating an interactive relationship with the existing customers and potential customers that result into long term relationship and increase in profitability in the future. Moreover, Buttle (1996) showed that good relationship in the marketing process is when having a 
International Journal of Business Management, Entrepreneurship and Innovation, Volume 2, Issue 1, 2020, PP 36-51, ISSN 2707-8027

[IJCAB

relationship with other stakeholders such as suppliers and shareholders that forms part of the organization. Also, the theory contends that the expense of holding an old client is far lower than the cost of building up another client. Additionally, Jackson (1985) clarified that the pith of relationship advertising is to draw in, build up and keep up an intimate association with big business clients.

Nevertheless, relationship marketing theory was criticized by scholars. It was established that it could be complicated to effectively measure the impact of offers by individual promoting or client support activities (Gummerus, Koskull \& Kowalkowski, 2017). Also, the theory is very much difficult to implement in the organization as it requires an immediate shift in the mindset of the companies who are familiar with the traditional marketing strategy. Another criticism for the most part for littler organizations are the time, cash, and skill required to appropriately set up all the social correspondence channels and advertising endeavors (Cacciolatti \& Lee, 2016). Moreover, the theory was much relevant to the study and the content of the argument was helpful. The approach showed relationship marketing involved interaction marketing, database marketing and network marketing. Database advertising is the utilization of data innovation to utilize the accessible innovation in the business to help increment the unwaveringness of the clients and ensure the satisfaction of the customers. The theory was applicable and it informed the dependent variable, customer loyalty. Maintaining a good relationship with the customers changes their perception towards other organization producing the same products and service and in return, they purchase more of the products that they trust most despite the circumstance.

\section{Empirical Review}

Nguyen, Nguyen and Phan (2018) reviewed the content of the fulfillment and loyalty of the clients in the Vietnamese security setting. The examination embraced the descriptive research plan and focused on the population of 1476, while the sample size was 275 . The discoveries of the investigation found that life-insurance setting organizations should concentrate on the satisfaction of the customers to stimulate performance. Olumoko, Dansu and Abass (2014) analyzed the role of personal selling in upgrading client satisfaction in the Nigerian insurance market. The focused population of the investigation was 110 respondents. The discoveries of the examination proclaimed that a person selling system is the most valuable promoting specialized device that ought to be grasped by Nigerian firms. It might likewise be utilized to improve the picture of the business. An examination was conducted by Auka et al. (2015) to explore the causes of customer loyalty in retail banking in Kenya and found that every one of the parts of administration quality impacts customer loyalty in retail banking

Ondieki et al. (2014) inspected how direct selling systems used by business banks in Kisii County influence client dependability and its activity on client maintenance. The investigation embraced a quantitative methodology with a descriptive research overview that enabled a specialist to gather essential quantitative information through organized surveys. The entire population was 983 respondents and the sample size was 283 , comprising sales representatives, customers and project leaders. The discoveries of the examination illustrated institutions to use individuals selling techniques for expanding volume sales. The examiner recommended the establishment of a valuable, direct arrangements approach that ensures productive client maintenance use program. Banerje (2014) analyzed the roles of personal selling in upgrading 'customer satisfaction' in the Indian home insurance market. The investigation embraced the descriptive cross-sectional study and the focused on population was 100. The discoveries of the examination perceived that Personal 
International Journal of Business Management, Entrepreneurship and Innovation, Volume 2, Issue 1, 2020, PP 36-51, ISSN 2707-8027

[IJCAB

selling has plenty of points of interest that could achieve a whole deal business association between the two social events drew in with a protection contract. The results in like manner exhibited that personal selling ensures that customers get the exact idea of the organization they require because, with particular trading, things and information could be changed to suit precise needs. The investigation suggested the number of personal sales ought to be expanded with the goal that clients will get increasingly essential data about home insurance.

Tapera and Gororo (2016) conducted a study to examine the viability of advertising procedures utilized by Zimbabwean Insurance organizations for making a competitive advantage. The particular goals of the investigation were to investigate the impact of promoting, web showcasing and staff selling methodology on making an upper hand. A cross-sectional study system was utilized to assemble information from the sample of associations inside the insurance business. The discoveries of the investigation built up that individual selling and publicizing were used as the special principle procedures. An examination was conducted by Mbugua (2014) to break down the proper selling techniques and execution of pharmaceutical firms in Nairobi. The investigation found that the pharmaceutical firms were using individual selling procedures to promote their things and it realized improved performance as far as a progressively critical volume of offers, quicker development of medications, balanced overall revenue, pharmaceutical firm instruction and sponsorship of occasions and expanded money related performance. Cheserem (2016) reviewed the Importance of Marketing Mix Strategies on Client Commitment to Fast Food Establishments in Nairobi. The discoveries of the investigation indicated that description, item marketing, value ambitions and location are entirely connected with customer loyalty. The examination also found out that the employment of the advertising channels doesn't focus on the intrigue satisfaction by offering stock; however, the need to animate demands through information, making kinship and progression to the client. The examination presumed that client dedication is one of the markers of business execution measurements.

A study was conducted by Moghareh Abed and Haghighi (2016) to look at the impact of selling procedures on deals execution in the protection firms working in Bingley, United Kingdom. The particular goals that guided the examination were to research the effects of customer- oriented selling, versatile selling, social methodology on sales performance. The findings of the investigation indicated that managers' impression of the reception of systems concerning the selling firm is associated with the allocation of some particular classes of practices which can add to the making of stable and long- lasting positive association with clients which can add to the formation of genuine and long-term positive association with customers. Adesoga (2016) examined the relevance of personal selling in selected Bottling Companies in Lagos State, Nigeria. The unit of analysis was the managers from different departments and the targeted population was 57 respondents. The examination uncovered that personal selling emphasizes relationship building, encourages an innovative sale, and spoke to the organization well to the customers. The investigation inferred that individual trading was up 'til now pertinent and an essential accomplishment factor in the present promoting practices regardless of the presence of advanced advertising. Overseers stressed over the focused point in the market advantage should consider the personal selling approach.

Carelse (2017) researched the effect of administration quality and customer fulfillment on customer loyalty in life insurance in South Africa. The examination embraced a descriptive exploration plan. The sample size of the study was 398. The discoveries of the investigation 
International Journal of Business Management, Entrepreneurship and Innovation, Volume 2, Issue 1, 2020, PP 36-51, ISSN 2707-8027

@JCAB

indicated that improving the nature of the administration offered to the customers and developing to give clarifications to the item that it can take care of their issues increment their loyalty.

Waithaka (2014) studied the impact of client upkeep systems on the show of protection organizations in Nairobi, Kenya. The focused on population comprised of the 48 insurance companies and a census was carried out. The study showed that customer retention was positively related to the performance of the companies. Further, the examiner concluded that organizations ought to reinforce their customer securities to expand customer maintenance, increment piece of the pie just as develop their business volumes. The investigation advocated that organizations ought to improve their market shrewdness to distinguish new patterns in business sectors only as a rivalry. Ayimey et al. (2013) examined the impact of client management and client maintenance systems on the presentation of two life insurance in Ghana. Information was gathered through meetings with the policyholders and questionnaires directed to the supervisory groups. The discoveries of the investigation demonstrated differences in customer retention strategies regarding healthy communication with customers and offer of the bonuses were undoubtedly connected with customer satisfaction. The study recommends building associations with clients and ensuring satisfactory policyholders to enhance the performance of the companies.

Mamo (2015) initiated an examination to analyze the adequacy of individual selling practices on the performance of NIB Insurance SC in Ethiopia. The quantitative data was gathered by the utilization of the survey and personal information from the meeting guide. The discoveries of the examination set up that specific selling procedure were undoubtedly identified with the performance of the NIB insurance organization. In Tanzania, Magasi (2015) examined customer relationship management and its effect on client maintenances in the bank. The research focused on clients' trust, fulfillment and the clients' support. The study concluded that Customer relationship management might work if the three fundamentals are utilized together and not independently. Further, Oketch (2014) analyzed the difficulties of customer retention by the Madison insurance organization in Kenya. The investigation found that there are different estimates set up to hold the customers at the organization, including a devoted customer administration office, streamlining claims the board, recharging sees the executives and typical subsequent meet-ups to the customers. Additionally, the examination likewise uncovered the essential difficulties of holding the customers were the external, which was raised through customer desires, nature of customers and trust, among others.

\section{Conceptual Framework}

The structure encourages the researcher to see the proposed associations between the variables in the assessment. Figure 1 preset the conceptual framework. 
International Journal of Business Management, Entrepreneurship and Innovation, Volume 2, Issue 1, 2020, PP 36-51, ISSN 2707-8027

\section{[IJCAB}

\section{Independent Variables}

\section{Canned Personal Selling Strategy}

- Providing incentives to customers

- Clear Description of products

- Tracking the customers

System Personal Selling Strategy

- persistent communication

- Sells products as a package

- interlocking goods and integrated services

\section{Features Personal Selling Strategy}

- Relate features to consumer benefit

- Presentation of contents of goods

- Adopting consumer needs

\section{Consultative Personal selling Strategy}

- Building a relationship

- Identifying solutions

- active listening

\section{Figure 1: Conceptual Framework}

Source: Researcher, 2020

\section{Research Methodology}

This study adopted the descriptive research design, which depicted the attributes of a specific circumstance, occasion, or case. According to Patten and Newhart (2017), the descriptive study design is utilized when gathering data about individuals' attitudes, opinions and habits. The targeted population was 967 employees working in the selected four insurance companies in Malindi, namely; Gateway insurance company limited, Marangi insurance agency, Blue shield Company Limited, Tausi Insurance Agency. The unit of analysis was sales managers, salespersons and the customers. Questionnaires were circulated directly to the sales managers, salespersons and customers in four selected insurance companies in Malindi. The duly filled questionnaires were then picked after one week.SPSS was used to organize code and analyze data and generate the quantitative report. The examination was developed using both descriptive and inferential statistics. The correlation presented the association between the variables, while the regression depicted the relationship between the variables under investigation. ANOVA examination quantified the best fit and determined if the general model was statistically significant. 
International Journal of Business Management, Entrepreneurship and Innovation, Volume 2, Issue 1, 2020, PP 36-51, ISSN 2707-8027

[IJCAB

\section{Data Analysis and Discussion}

\subsection{Correlation Analysis}

Correlation is a term used to indicate the association between variables (Porth, White, Jaquish \& Ritland, 2018). A correlation coefficient of +1 shows a perfect positive association, while -1 demonstrates a perfect negative association. A correlation coefficient of zero shows no association (Gogtay \& Thatte, 2017). The correlation results are presented in Table 1.

\section{Table 1: Multiple Correlation Analysis Results}

\begin{tabular}{|c|c|c|c|c|c|c|}
\hline Correlations & & $\begin{array}{c}\text { Customer } \\
\text { Loyalty }\end{array}$ & $\begin{array}{c}\text { Canned } \\
\text { Strategy }\end{array}$ & $\begin{array}{l}\text { Systems } \\
\text { Strategy }\end{array}$ & $\begin{array}{l}\text { Features } \\
\text { Strategy }\end{array}$ & $\begin{array}{c}\text { Consultative } \\
\text { Strategy }\end{array}$ \\
\hline Customer & Pearson & & & & & \\
\hline Loyalty & $\begin{array}{l}\text { Correlation } \\
\text { Sig. (2- } \\
\text { tailed) }\end{array}$ & 1.000 & & & & \\
\hline Canned & Pearson & & & & & \\
\hline Strategy & $\begin{array}{l}\text { Correlation } \\
\text { Sig. (2- } \\
\text { tailed) }\end{array}$ & $\begin{array}{l}.554 * * \\
0.000\end{array}$ & 1.000 & & & \\
\hline Systems & Pearson & & & & & \\
\hline Strategy & $\begin{array}{l}\text { Correlation } \\
\text { Sig. (2- } \\
\text { tailed) }\end{array}$ & $\begin{array}{l}.518 * * \\
0.000\end{array}$ & $\begin{array}{l}.441 * * \\
0.000\end{array}$ & 1.000 & & \\
\hline Features & Pearson & & & & & \\
\hline Strategy & $\begin{array}{l}\text { Correlation } \\
\text { Sig. (2- } \\
\text { tailed) }\end{array}$ & $\begin{array}{l}.549 * * \\
0.000\end{array}$ & $\begin{array}{l}.439 * * \\
0.000\end{array}$ & $\begin{array}{l}.504 * * \\
0.000\end{array}$ & 1.000 & \\
\hline Consultative & Pearson & & & & & \\
\hline Strategy & $\begin{array}{l}\text { Correlation } \\
\text { Sig. (2- } \\
\text { tailed) }\end{array}$ & $.588 * *$ & $\begin{array}{l}.542 * * \\
0.000\end{array}$ & $\begin{array}{l}.551^{* *} \\
0.000\end{array}$ & $\begin{array}{l}.473^{* *} \\
0.000\end{array}$ & 1.000 \\
\hline
\end{tabular}

The results in Table 1 showed that canned personal selling strategy $(\mathrm{r}=0.554, \mathrm{p}=0.000)$ had a positive and significant association with customer loyalty. Systems' selling Strategy and customer loyalty were positively and significantly associated $(\mathrm{r}=0.518, \mathrm{p}=0.000)$. Features personal selling strategy was positively and significantly associated with customer loyalty $(r=0.549, p=0.000)$. Finally, consultative personal selling strategy was positively and significantly associated with customer loyalty $(\mathrm{r}=0.588, \mathrm{r}=0.000)$. This implied that the Consultative personal selling strategy was the most variable that affected customer loyalty among the selected insurance companies. The results agreed with the findings of Cheserem (2016), who showed that the job of the marketing channels does not concentrate on the interest fulfillment by offering merchandise but the need to stimulate requests through data, making friendship and advancement to the customer. Also, Ayimey, Awunyo-Vitor and Abdulai (2013) indicated contrasts in client maintenance systems regarding ordinary correspondence with customers and offer of the rewards were connected $\mathrm{d}$ with consumer loyalty 
International Journal of Business Management, Entrepreneurship and Innovation, Volume 2, Issue 1, 2020, PP 36-51, ISSN 2707-8027

[IJCAB

\subsection{Regression Analysis}

The results presented in table 2 indicate the fitness of model.

Table 2: Model Fitness

\begin{tabular}{lllll} 
Model & R & R Square & Adjusted R Square & Std. Error of the Estimate \\
\hline & & & \\
1 & $.705 \mathrm{a}$ & 0.697 & 0.685 & 0.28367 \\
\hline a. & $\begin{array}{l}\text { Predictors: (Constant), Canned personal selling strategy, system personal selling strategy, } \\
\text { features personal selling strategy and consultative personal selling strategy }\end{array}$
\end{tabular}

The model fitness results in Table 2 show that canned personal selling strategy, system personal selling strategy, features personal selling strategy and consultative personal selling strategy were seen as acceptable factors in clarifying client loyalty with $\mathrm{R}$ square of 0.697 . This means that independent variables explained $69.7 \%$ of the variations in customer loyalty. The outcomes were in agreement with the discoveries of Auka, Bosire and Matern (2015) who demonstrated that every one of the components of administration quality affect client reliability in retail banking

Table 3: ANOVA

\begin{tabular}{llccccc}
\hline Model & & Sum of Squares & df & Mean Square & F & Sig. \\
\hline 1 & Regression & 12.881 & 4 & 3.22 & 64.40 & $.000 \mathrm{~b}$ \\
& Residual & 13.036 & 246 & 0.05 & & \\
& Total & 13.888 & 250 & & & \\
\hline
\end{tabular}

a. Dependent Variable: Customer Loyalty

b. Predictors: (Constant), Canned personal selling strategy, system personal selling strategy, features personal selling strategy

The results show that independent variables were good indicators of customer loyalty. This was supported by a F measurement of 64.40 and the detailed $p$ value $(0.000)$ which was less than 0.05 significance level. Therefore, the model was statistically significant

The multiple regression of coefficient is presented in Table 4.

Table 4: Multiple Regression Results

\begin{tabular}{llccccc}
\hline Model & & \multicolumn{2}{c}{$\begin{array}{c}\text { Unstandardized } \\
\text { Coefficients } \\
\text { B }\end{array}$} & $\begin{array}{c}\text { Standardized } \\
\text { Coefficients } \\
\text { Beta }\end{array}$ & t & Sig. \\
\hline \multirow{1}{*}{$\mathbf{1}$} & 2.175 & 0.121 & & 18.039 & 0.000 \\
& $\begin{array}{l}\text { (Constant) } \\
\text { Canned }\end{array}$ & 0.137 & 0.04 & 0.24 & 3.469 & 0.001 \\
& $\begin{array}{l}\text { Strategy } \\
\text { System }\end{array}$ & 0.082 & 0.041 & 0.144 & 2.014 & 0.046 \\
& $\begin{array}{l}\text { Strategy } \\
\text { Feature }\end{array}$ & 0.142 & 0.039 & 0.248 & 3.632 & 0.000 \\
$\begin{array}{l}\text { strategy } \\
\text { Consultative }\end{array}$ & 0.137 & 0.039 & 0.261 & 3.528 & 0.001 \\
\hline
\end{tabular}


International Journal of Business Management, Entrepreneurship and Innovation, Volume 2, Issue 1, 2020, PP 36-51, ISSN 2707-8027

[IJCAB

Canned personal selling strategies and customer loyalty were positively and significantly related ( $\beta=0.137, p=0.001)$, as shown in table 4 . Personal selling strategy and customer were positively and significantly related $(\beta=0.082, p=0.046)$. Features personal selling strategies and customer loyalty were positively and significantly related $(\beta=0.142, p=0.000)$. Finally, consultative personal selling strategy was positively and significantly related to customer loyalty $(\beta=0.137, \mathrm{p}=0.001)$. This implied that an improvement in canned personal selling strategy, system personal selling strategy, features personal selling strategy and consultative personal selling strategy led to an increase in customer loyalty in the selected insurance companies in Malindi. The regression results consisted of those of Nguyen, Nguyen and Phan (2018), who found that life insurance firms should concentrate on improving help quality and corporate picture to get consumer loyalty that prompts client dedication. Additionally, Tapera and Gororo (2016) built up that individual selling and publicizing were primarily utilized as the principle limited time procedures to expand the deals.

\section{Conclusions}

The examination concludes that the canned sell technique impacts customer loyalty. The outcomes demonstrated that the canned selling procedure had a positive and critical relationship with customer loyalty. Besides, the findings showed that the canned individual selling technique had a positive and noteworthy association with customer loyalty. Moreover, the study concludes that a canned selling strategy could be achieved when the sales representatives of a company are involved in providing incentives sought by the buyers until a consensus has arrived. Furthermore, the study concludes that the system selling strategy had a positive and significant association with the customer's loyalty. Moreover, the study also establishes that the system's selling strategy had a positive and meaningful relationship with customer loyalty. The study further concludes that the system's selling strategy was so influential and is commonly used by many organizations, particularly the financial institutions in which the firms market their products through selling the products as a package instead of selling them separately.

Moreover, the study concludes that features selling strategy is positively and significantly associated with the loyalty of the customers. Likewise, the features selling strategy is positively and significantly related to customer loyalty. The study also concludes that features personal selling strategy is used by the companies and the salespersons associate the features and the content of the product to the benefits to the consumers. The examination confirms that the highlights of the items must be in a situation to address the issues of the planned purchasers. The study also concludes that the consultative selling strategy is positively and significantly associated with customer loyalty. The study further established that a consultative approach was positively and significantly related to customer loyalty. The study concludes that the consultative approach influences organizational performance through improved communication, reduced costs, increased productivity, quick decision making, increased organization flexibility and increased efficiency.

\section{Recommendations}

Since the canned selling strategy was positively and significantly associated, the insurance companies in Malindi can use the approach as a strategic action to enhance customer loyalty and counter competitive pressure in the industry. Moreover, companies should embrace and implement canned selling strategies to gain a competitive advantage against other players in the industry. Insurance companies need to use the canned approach as a strategic action to enhance customer loyalty and counter competitive pressure in the industry. The study also recommends that the insurance may introduce other systems of selling their products to the customers. Moreover, the 
International Journal of Business Management, Entrepreneurship and Innovation, Volume 2, Issue 1, 2020, PP 36-51, ISSN 2707-8027

[ICAB

research suggests that based on the level of completion in the market, the management in all insurance companies in Kenya to carry out various personal selling strategies to enable the companies to grow and diversify their portfolio to minimize losses and cut down the cost thus enhancing their competitiveness. Moreover, the study recommends systems selling strategies should be put in place to improve operational efficiency and improve the decision-making process to increase their performance.

Moreover, the insurance companies can be more involved in advocating selling their products by clearly establishing the features of a product before making the presentation. The study also recommends the insurance companies to be revealing all the components of any product without hiding any information. Based on the consultative selling strategy, the study recommends the insurance companies to increase the number of salespersons so that they may be responding to the grievances of the customers immediately. Following the entrant of new insurance companies in Kenya, the existing companies must come up with personal selling strategies that will ensure their survival in the increasingly volatile industry. The study also recommends the consultative approach is the most reliable. It has a significant influence influences on organizational performance since it improves communication, reduced costs, increased productivity, quick decision making, increased organization flexibility and increased efficiency.

\section{REFERENCES}

Adesoga, A. (2016). Examination of the Relevance of Personal Selling in Marketing Activities: a Descriptive Method. Journal of Accounting and Management, 6(2), 103-116.

Auka, D., Bosire, J. N., \& Matern, V. (2015). Perceived service quality and customer loyalty in retail banking in Kenya. British Journal of Marketing Studies 1, (3). 54-61,

Ayimey, E. K., Awunyo-Vitor, D., \& Abdulai, S. (2013). Influence of Customer Retention Strategies on performance of SIC Life Insurance Company Limited and StarLife Assurance Company Limited in Ghana: An Exploratory Assessment. International Journal of business and managermant, 7(3), 89-94

Banerjee, A. (2014). The role of personal selling in home insurance in Indian market. International Journal of Business and Management Invention, 2(1), 34-39.

Buttle, F. (Ed.). (1996). Relationship marketing: theory and practice. Sage.United Kingdom

Carelse, B. M. (2017). Investigating the impact of service quality and customer satisfaction on customer loyalty in life insurance in South Africa. South African Journal of Business Management, 5(3), 178-184

Cheserem, E. (2016). The Influence of Marketing Mix Strategies on Customer Loyalty in Fast Food Restaurants in Nairobi, Kenya. Unpublished MBA project, University of Nairobi.

Cooper, D. R., \& Schindler, P. S. (2014). Business Research Methods. Data Preparation and Description. McGraw-Hill Irwi. Boston

Cramphorn, S. (2006). How to use advertising to build brands: in search of the philosopher's stone. International Journal of Market Research, 48(3), 255-275.

Creswell, J. W., \& Poth, C. N. (2017). Qualitative inquiry and research design: Choosing among five approaches. Sage publications, United Kingdom

Cronbach, L. J. (1951). Coefficient alpha and the internal structure of tests. psychometrika, 16(3), 297-334.

Friman, M., Gärling, T., Millett, B., Mattsson, J., \& Johnston, R. (2002). An analysis of international business-to-business relationships based on the Commitment-Trust theory. Industrial marketing management, 31(5), 403-409. 
International Journal of Business Management, Entrepreneurship and Innovation, Volume 2, Issue 1, 2020, PP 36-51, ISSN 2707-8027

[IJCAB

Golafshani, N. (2003). Understanding reliability and validity in qualitative research. The qualitative report, 8(4), 597-606.

Hawaldar, I. T. (2018). Influence of advertisement on customers based on AIDA model. Problems and Perspectives in Management, 16(4), 285.

Javan, H. T., Khanlari, A., Motamedi, O., \& Mokhtari, H. (2018). A hybrid advertising media selection model using AHP and fuzzy-based GA decision making. Neural Computing and Applications, 29(4), 1153-1167.

Jumaev, M., \& Hanaysha, J. R. (2017). Impact of relationship marketing on customer loyalty in the banking sector. Far East Journal of Psychology and Business, 6(4), 36-55.

Khasaya, M. H. (2018). Marketing Mix and Adoption of Improved Sanitation Products among Rural Households in Magarini, Kilifi County Kenya (Doctoral dissertation, Kenyatta University).

Kimberlin, C. L., \& Winterstein, A. G. (2008). Validity and reliability of measurement instruments used in research. American journal of health-system pharmacy, 65(23), 2276-2284.

Kothari, C.R. (2004). Research methodology: Methods and techniques. New Delhi: New Age international. India.

Kwak, H., Anderson, R. E., Leigh, T. W., \& Bonifield, S. D. (2019). Impact of salesperson macroadaptive selling strategy on job performance and satisfaction. Journal of Business Research, 9(4), 42-55.

Lee, S., Song, H., Lee, C. K., \& Petrick, J. F. (2018). An integrated model of pop culture fans' travel decision-making processes. Journal of Travel Research, 57(5), 687-701.

Linge, T. K., \& Sikalieh, D. (2019). Influence of idealized influence on employee job performance in the insurance industry in Kenya. International Journal of Research in Business and Social Science 8(5), 266-273.

MacMillan, K., Money, K., Money, A., \& Downing, S. (2005). Relationship marketing in the notfor-profit sector: an extension and application of the commitment-trust theory. Journal of business research, 58(3), 806-818.

Malterud, K., Siersma, V. D., \& Guassora, A. D. (2016). Sample size in qualitative interview studies: guided by information power. Qualitative health research, 26(13), 1753-1760.

Mamo, S. (2013). An assessment of personal selling practice in NIB Insurance SC (Doctoral dissertation, St. Mary's University, Ethiopia).

Mbugua, D. M. (2014). Personal Selling Strategies and Performance of Pharmaceutical Firms In Nairobi, Kenya. (Master Thesis, University of Nairobi)

Moghareh Abed, G., \& Haghighi, M. (2016). The effect of selling strategies on sales performance: Case study of insurance firms in Bingley, United Kingdom. Business Strategy Series, 10(5), 266-282.

Möller, K., \& Halinen, A. (2000). Relationship marketing theory: its roots and direction. Journal of marketing management, 16(1-3), 29-54.

Morgan, R. M., \& Hunt, S. D. (1994). The commitment-trust theory of relationship marketing. Journal of marketing, 58(3), 20-38

Mugenda, O. M \& Mugenda, A. G. (2008) Research methods: Quantitative and qualitative approaches. Acts Press. Nairobi

Nguyen, H., Nguyen, H., Nguyen, N., \& Phan, A. (2018). Determinants of customer satisfaction and loyalty in vietnamese life-insurance setting. Sustainability, 10(4), 1151.

Njoroge, B. K. (2019). Determinants of corporate sustainability disclosure among large firms in Kenya (Doctoral dissertation, Strathmore University). 
International Journal of Business Management, Entrepreneurship and Innovation, Volume 2, Issue 1, 2020, PP 36-51, ISSN 2707-8027

[IJCAB

Ocon, J. A. C., \& Alvarez, M. G. (2014). The Implication of Personal Selling Strategies in Motivation, Approaches and Good Grooming. Procedia-social and behavioral Sciences, 155, 53-57.

Oketch, S. (2014). Challenges of Customer Retention by Madison Insurance Company Limited in Kenya. Master Thesis, University of Nairobi.

Olumoko, T. A., Dansu, S. F., \& Abass, O. A. (2012). The role of personal selling in enhancing client satisfaction in Nigerian insurance market. Journal of Emerging Trends in Economics and Management Sciences, 3(2), 147-152.

Ondieki, S. M., Okibo, W. B. A., Nyang'au, A., Obenge, P. O., Nyongesa, W. J., \& Nyamasege, D. (2014). Effects of direct selling strategy on customer loyalty by commercial banks in Kisii County. International Journal of Business and Social Science, 5(3).

Parente, P. M., \& Silva, J. M. S. (2016). Quantile regression with clustered data. Journal of Econometric Methods, 5(1), 1-15

Patten, M. L., \& Newhart, M. (2017). Understanding research methods: An overview of the essentials. Routledge. London

Porth, I., White, R., Jaquish, B., \& Ritland, K. (2018). Partial correlation analysis of transcriptomes helps detangle the growth and defense network in spruce. New Phytologist, 218(4), 1349-1359.

Rahi, S. (2017). Research design and methods: A systematic review of research paradigms, sampling issues and instruments development. International Journal of Economics \& Management Sciences, 6(2), $1-5$.

Rehman, F., Nawaz, T., Khan, A., \& Hyder, S. (2014). How Advertising Affects the Buying Behavior of Consumers in Rural Areas: A Case of Pakistan. Academic Research International, 5(4), 405-412.

Saunders, M., Lewis, P., \& Thornhill, A. (2012). Research methods for business students. Harlow: Pearson. London.

Taber, K. S. (2018). The use of Cronbach's alpha when developing and reporting research instruments in science education. Research in Science Education, 48(6), 1273-1296.

Tapera, J., \& Gororo, R. (2013). An investigation into the effectiveness of marketing strategies employed by Zimbabwean Insurance companies for creating competitive advantage. Internal journal of marketing, 4(2), 78- 86.

Waithaka, L. W. (2014). Influence of customer retention strategies on performance of insurance companies in Nairobi, Kenya. Doctoral Thesis, University of Nairobi.

Wijaya, B. S. (2015). The development of hierarchy of effects model in advertising. International Research Journal of Business Studies, 5(1), 75-82

Zinkhan, G. M. (2002). Relationship marketing: Theory and implementation. Journal of Market-Focused Management, 5(2), 83-89.

This is an open-access article published and distributed under the terms and conditions of

the cc) Creative Commons Attribution 4.0 International License of United States unless otherwise stated. Access, citation and distribution of this article is allowed with full recognition of the authors and the source.

Authors seeking to publish with an Internationally Peer Reviewed Journals should consider https://www.ijcab.org/ by writing to the Editor at editor@ijicab.org or submitting online at https://journals.ijcab.org/journals/index.php. The articles must be quality and meet originality test.

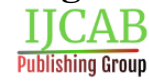

